\title{
A Promising Technological Approach to Improve Indoor Air Quality
}

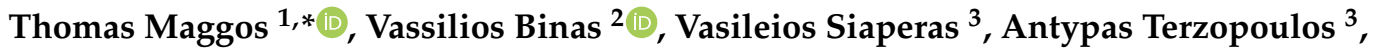 \\ Panagiotis Panagopoulos ${ }^{1}$ and George Kiriakidis ${ }^{2}$ \\ 1 Environmental Research Laboratory, NCSR “Demokritos”, 15310 Ag. Paraskevi, Athens, Greece; \\ ppanag.uoi@gmail.com \\ 2 Institute of Electronic Structure and Laser, Foundation for Research and Technology, 70013 Heraclion, Crete, \\ Greece; binasbill@iesl.forth.gr (V.B.); kiriakid@iesl.forth.gr (G.K.) \\ 3691 Industrial Base Factory, 19011 Avlonas, Greece; bsiaper@gmail.com (V.S.); antyterzo@gmail.com (A.T.) \\ * Correspondence: tmaggos@ipta.demokritos.gr; Tel.: +30-210-6503716
}

Received: 18 September 2019; Accepted: 5 November 2019; Published: 12 November 2019

check for updates

\begin{abstract}
Indoor Air quality (IAQ) in private or public environments is progressively recognized as a critical issue for human health. For that purpose the poor IAQ needs to be mitigated and immediate drastic measures must be taken. In environmental science and especially in advanced oxidation processes and technologies (AOPs-AOTs), photocatalysis has gained considerable interest among scientists as a tool for IAQ improvement. In the current study an innovative paint material was developed which exhibits intense photocatalytic activity under direct and diffused visible light for the degradation of air pollutants, suitable for indoor use. A laboratory and a real scale study were performed using the above innovative photo-paint. The lab test was performed in a special design photo-reactor while the real scale in a military's medical building. Nitrogen Oxide (NO) and Toluene concentration was monitored between "reference" rooms (without photo paint) and "green" rooms (with photo-paint) in order to estimate the photocatalytic efficiency of the photo-paint to degrade the above pollutants. Results of the study showed a decrease up to $60 \%$ and $16 \%$ for $\mathrm{NO}$ and toluene respectively under lab scale tests while an improvement of air quality up to $19 \%$ and $5 \%$ under real world conditions was achieved.
\end{abstract}

Keywords: IAQ improvement; photo-paint; NO; Toluene degradation

\section{Introduction}

Indoor air quality (IAQ) is an important determinant of human health, comfort and productivity. For that purpose, high quality indoor air is desirable. Indoor air pollution can be addressed through the two approaches of prevention and removal. The latter includes the use of air cleaning technologies especially in buildings where ventilation rates are being reduced in order to save energy. Indicative air cleaning technologies which have been developed during the recent years are: filtration and adsorption, electrostatic air purification, air filtration and gas adsorption filtration [1-3], ozonation [4-7], non-thermal plasma [8,9] and photocatalytic oxidation (PCO) [10-13]. PCO is a general air cleaning technology, which is able to degrade Volatile Organic Compounds (VOCs), such as aromatics, alkanes, odor compounds etc. Air cleaning photocatalytic technology is based on the principle that radiation of suitable wave-lengths can be absorbed by semiconductors, which leads to the creation of reactive oxygen species (ROS) that can degrade air pollutants. $\mathrm{TiO}_{2}$ is the most commonly-used semiconductor in PCO research. However, over the last years, scientists have combined $\mathrm{TiO}_{2}$ with other materials such as activated carbon and zeolite hybrid catalysts in order to enhance the PCO degradation of air pollutants [14-16]. Furthermore, numerous $\mathrm{TiO}_{2}$ photocatalysts with different morphological designs 
have been developed: nanoparticles, nanotubes, hollow fibers and mesoporous. To this end, the need to evaluate the photocatalytic performance of the above materials in a common methodological approach has been raised and extensive research efforts have been devoted to it $[17,18]$.

However, in most of these studies, only a single compound was tested, using a photocatalytic reactor and a methodological approach, which have been developed by the same lab that produced the material. It is well known that indoor air contains numerous contaminants; thus, tests of only one compound may be misleading. Furthermore, many studies proved the generation of by-products during the photocatalytic processes, such as formaldehyde, ozone, benzaldehyde, acetaldehyde etc. It is obvious that in some cases, by-products could be more harmful than the target pollutant [19-22]. For that purpose, and although photocatalytic technology is promising, the synthesis route of a photocatlytic material should be designed carefully in order to avoid contaminants which could lead to the formation and emission in the gas phase of intermediate products as they can be more hazardous than the target pollutant. The latter is clearly demonstrated during the evaluation of two photocatalytic air-purification in a mock-up air cabin. Although two symptoms, dizziness and claustrophobia, were reported to decrease when either one of the photocatalytic air-purification devices was operated, intermediates (acetaldehyde and formaldehyde) were detected as a result of ethanol photodegradation [23,24].

The present research addresses the indoor air purification study using a photocatalytic paint, which was tested under both laboratory and real world indoor conditions (application in building walls). A modified $\mathrm{TiO}_{2}$ was chosen as photocatalyst in order to be activated by visible light which is the dominant spectrum in indoor environments. Traditional $\mathrm{TiO}_{2}$ is activated only under UV light. More specifically a Mn-doped $\mathrm{TiO}_{2}$ photocatalyst (powder) was used in the synthetic route of a photocatalytic paint production. The powder named TCM-1 [25] has already been successfully tested for the oxidation of air pollutants under indoor-like illumination conditions and when mixed either with calcareous or cementitious base matrices demonstrated a unique ability to efficiently degrade volatile organic compounds (VOCs) such as BTX (Benzene, Toluene, Xylene), formaldehyde and nitrogen oxides (NOx) [26-28]. Additionally, it has been proven effective on eliminating bacteria such as E. coli and Klebsiella pneumoniae and phages such as MS2 [29-32]. Furthermore, no dangerous by-products were produced during the degradation process. In a previous work, in order to demonstrate the photocatalytic effectiveness of TCM-1, the powder has been incorporated in/on different construction matrices such as glass, plywood, wood, ceramic and concrete substances, which were, subsequently, tested indicating very promising results [33].

In the current study TCM-1 incorporated into paint production process in order to produce paint with the ability to photocatalytically improve IAQ by degraded indoor air pollutants. NO and toluene were chosen as the target pollutants since they are typical indoor air pollutants that can be emitted from various indoor sources, such as cooking, tobacco smoke, furniture, building materials and fireplaces, as well as from outdoor sources, e.g., traffic, domestic heating. These indoor pollutants can have significant health impacts and for that purpose their elimination from the indoor environment should be appropriately addressed. In order to simulate the real indoor air conditions, visible light was used as the source for the PCO reaction in the current study. The latter is different from what we usually find in the literature. More specifically, UV light is the most commonly used parameter in the experimental procedures, which usually applied to test the efficiency of a photo-material.

The experimental study of the current work was carried out using the European Committee for Standardization (CEN) Technical Specification (TS) 16980:2016 as a basic reference to perform the lab scale experiments, while the real scale experiments were based on the comparison between the concentration level of a pollutant in a reference and the "green" room, respectively. The latter was performed at the military medical center of the Cadets Training Camp in Heraklion Crete. 


\section{Materials and Methods}

\subsection{Materials}

Chemicals for the preparation of the photocatalytic powder such as Titanium (IV) oxysulfate hydrate (TiOSO4·xH2O), manganese (II) acetate tetrahydrate $\mathrm{Mn}(\mathrm{CH} 3 \mathrm{COO}) 2)$ and ammonium hydroxide $(25 \% \mathrm{NH} 4 \mathrm{OH})$ purchased from Aldrich were applied.

Chemicals for the preparation of the photo-paint were purchased from VINAVIL EGYPT (New Cairo, Egypt), DOW chemicals (Midland, Michigan, MI, United States), BYK (Wesel, Germany), DuPont (Midland, Michigan, MI, United States) and Dionyssos Marbles (Penteli, Greece) and are readily available raw materials mainly used at the coating industry.

\subsection{Methods}

\subsubsection{Preparation of Photo-Material (powder)}

In the present study, an optimum powder ( $0.1 \%$ Mn-doped) named TCM- 1 was used for the preparation of photocatalytic paint. TCM-1 was synthesized by a co-precipitation method with $0.1 \%$ of manganese. TCM- 1 was precipitated at $\mathrm{pH} \sim 7$ from aqueous solution of titanium (IV) oxysulfate hydrate and manganese by the addition of ammonia. After aging the suspension overnight, the precipitate was filtered and dried under air at $373 \mathrm{~K}$. The residue was crushed to a fine powder and calcined in a furnace at $973 \mathrm{~K}$ for $3 \mathrm{~h}$. More details in the synthesis procedure and the characterization are given in previous work along with the preparation details [25].

\subsubsection{Preparation of Photo-Paint}

TCM-1 powder ( $0.1 \%$ Mn-doped) was added to a specially formulated architectural coating. The paint was consisted $10 \% \mathrm{w} / \mathrm{w}$ of the TCM-1 powder partly replacing the Titanium Oxide (normally used as a white pigment). The raw materials for the preparation of the photo-paint are commonly used in the coating industry. A polyvinyl acetate copolymer binder was used and the Pigment Volume Content (PVC) was adjusted, but kept below its critical value in order for the paint to have a high quality, matte finish.

The production process of the photo-paint was consisted of three discreet phases. At phase 1, the mill-base (the minimum amount of liquid that can wet the solid particles of the paint, added at phase 2) was produced. Water was used as solvent with additives, such as sodium hexametaphosphate (dispersion agent), propylene glycol (antifreezing agent), silica modified surfactant (defoaming agent), cellulose (rheology modifier), isothiazolinone based mixture (biocide agent) and a mixture of Alkanol-amines (pH adjusting agent). At phase 2, we applied high shear forces to the mill-base by using a disperser equipped with a blade dissolver disc and gradually added the solid phase of the paint [Calcium carbonate powder $(20 \mu \mathrm{m})$, Titanium Oxide $(0.2-0.5 \mu \mathrm{m})$, Talc Powder $(6 \mu \mathrm{m})$ and TCM-1 powder]. The goal of this phase is to maximize dispersion by eliminating the presence of any agglomerate in the final paint. At phase 3, we added the Polyvinyl Acetate copolymer binder emulsion and a coalescent solvent mixture, necessary for the final product to have a smooth surface (filmer). The dispersion was achieved by using low shearing forces and the pigment dispersion was stabilized in order to prevent the formation of uncontrolled flocculates by using non-ionic urethane rheology modifiers.

\subsection{Characterization}

Powder X-ray diffraction patterns were obtained by a Rigaku D/MAX-2000H rotating anode diffractometer ( $\mathrm{CuK} \alpha$ radiation) equipped with a secondary pyrolytic graphite monochromator operating at $40 \mathrm{kV}$ and $80 \mathrm{~mA}$ over the $2 \theta$ collection range of $20-80^{\circ}$ (scan rate was $0.05^{\circ} \mathrm{s}^{-1}$ ). The grain 
size $(\mathrm{nm})$ of TCM-1 was calculated from the line broadening of the X-ray diffraction peak according to the following Scherrer formula:

$$
D=k \lambda / \beta \cos \theta
$$

where $\mathrm{k}$ is the Scherrer contact $(\sim 0.9), \lambda$ is the wavelength of the $\mathrm{X}$-ray radiation (1.54 $\mathrm{A}$ for CuK $\alpha)$, $\beta$ is the full width at half maximum (FWHM) of the diffraction peak measured at $2 \theta$, and $\theta$ is the Bragg angle. The morphology and elemental analysis were performed using scanning electron microscopy (SEM) and energy dispersive X-ray spectroscopy (EDX), on a JSM-6390LV microscope (Jeol, Tokyo, Japan).

The photo-paint was evaluated through typical quality control measurements. Viscosity was measured using a Brookfield KU-2 viscometer (Brookfield Engineering Laboratories, INC. Middleboro, MA, USA) at a temperature of $25^{\circ} \mathrm{C}$ with the help of a laboratory water bath and the measurements were conducted according to ASTM D 562-10 (2018) standard test method.. Density was measured using a $100 \mathrm{ml}$ pyknometer (density cup) by Elcometer (Manchester, United Kingdom) and an analytical scale, and the measurements were conducted according to ISO 2811 -1:2016 standard. Fineness of Grind was evaluated using a Hegman gauge and the evaluation was conducted according to ASTM D 1210-05 (2014) standard test method. Lastly, pH was measured using a Hanna HI 83141V pH meter (Hanna Instruments, Greece) and the measurements were conducted according to ISO 787-7:2009 standard.

\subsection{Photocatalytic Evaluation_Lab-Scale}

The experimental methodology that was applied and the required scientific equipment were based on CEN Technical Specification (TS) 16980:2016. The photocatalytic effect of the optimized material studied in a continuous flux photocatalytic reactor (Figure 1), which consists of a) a gas transfer and mixing unit in order to adjust the concentration and humidity levels; $b$ ) the photocatalytic reactor main body made of special plastic so as radiation intensity and wavelength of the radiation is not affected; (c) the sample irradiation system (OMICRON FS LED Rodgau-Dudenhofen, Germany) consisting of an LED device connected via software to a computer in order to achieve the optimum efficiency and accuracy in measuring the radiation; d) a NOx and VOCs analyzer installed on line with the reactor for continuous monitoring of the pollutant concentration.

Furthermore, in order to ensure optimum mixing of atmospheric pollutants in the reactor, a fan is installed inside the chamber, while its intensity is adjusted externally to ensure the stability of the experimental conditions throughout the experiments. The NO concentration is set to $(0.50 \pm 0.05)$ ppmv, while the relative humidity to $40 \pm 5 \%$. The illumination provided an average irradiance to the test specimen surface within the range of wavelengths that are mostly adsorbed by the photocatalyst, equal to $(10.0 \pm 5 \%) \mathrm{W} / \mathrm{m}^{2}$.

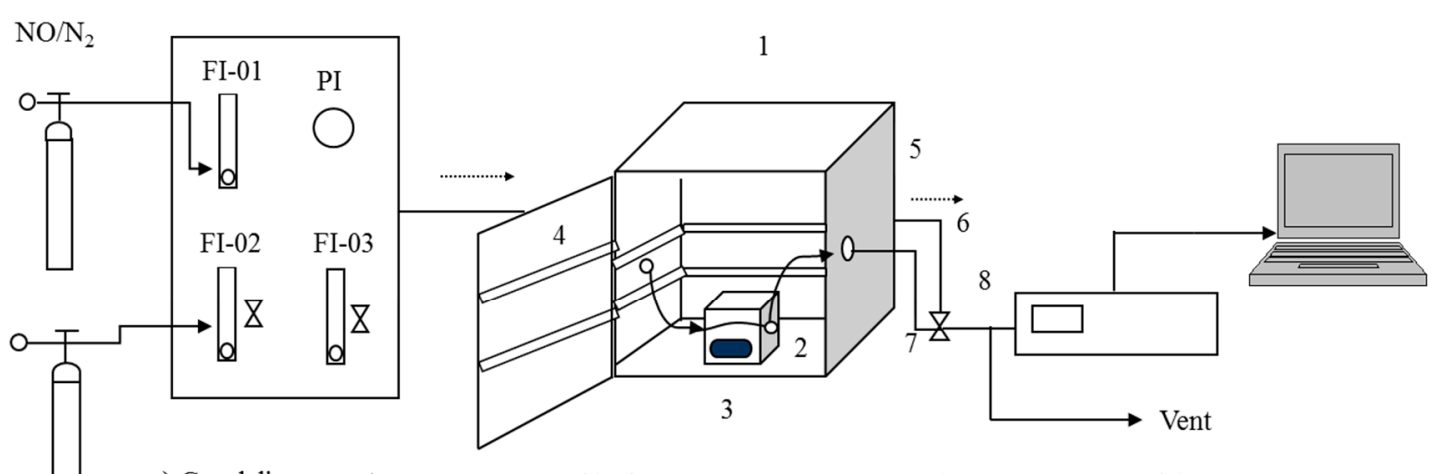
a) Gas delivery system
b) photoreactor
c) Measurement unit/ $\mathrm{NOx}$

Zero air

Figure 1. Photocatalytic reactor. 


\subsection{Photocatalytic Evaluation_Real-Scale}

A building of the Hellenic Army in Crete was used to test the de-polluting efficiency of the photo-paint under real scale application. In general, the photocatalytic efficiency of a material while applied in a real scale environment and more specifically in indoor building environment could be estimated through two approaches:

a) A first approach could be the installation of air quality and environmental monitoring systems (passive inorganic (NO) and organic (BTX) samplers, temperature and humidity recorders) in the buildings prior to the application of the photo-paint. To that end, a reliable record on the concentration levels of air pollutants in the case study building (without the photo paint) for at least 12 months should be obtained. Accordingly, the photo-paint should be applied in the buildings and environmental parameters should be monitored through passive sampling techniques for another 12 months. The potential changes in the indoor air quality due to the photocatalytic action of the photo-paint will be recorded and quantified to illustrate the capability of the photo-paint to improve IAQ. A restriction of this approach could be the variations in outdoor air quality and meteorological conditions during the different sampling periods. In order to eliminate the effect of the above restrictions, the experiments has to take place the same season (e.g., winter) and the outdoor concentration should be considered on the final results.

b) A second approach to evaluate the efficiency of the photo-paints is to estimate the IAQ differences between "reference" rooms (without photo paint) and "green" rooms (with photo-paint), which are located on the same level (in a raw) and where the same activities take place. The current approach overcomes the restrictions of the previous one and for that purpose was used in the current study. More specifically a room of $120 \mathrm{~m}^{2}$ in the ground floor was paint with the innovative photocatalytic paint ("green room") and compared with a same size and usage room ("reference room") located very close to the "green" one. The outcome of this approach was compared with the outcome of the lab tests in order to estimate the differences of the photocatalytic performance of a material when studied in a control experimental reactor and under real world environmental conditions. Passive samplers for NO and Toluene were applied. More specifically, four passive samplers/pollutants were installed in each of the rooms for 30 days and then analyzed in the lab using the well-established Saltzmann spectrophotometric method for NO, while the Toluene samplers were and desorbed by carbon disulphide and analyszed by gas chromatography (GC/FID).

\section{Results}

\subsection{Physical and Chemical Properties}

Figure 2 shows the X-Ray Difraction (XRD) pattern of TCM- 1 (dopant concentration $0.1 \mathrm{wt} \%$ ), calcinated at $700^{\circ} \mathrm{C}$ for $3 \mathrm{~h} 1$. The peaks at $2 \theta$ values of $25.3^{\circ}, 37.6^{\circ}$, and $48.2^{\circ}$ correspond to the (101), (004) and (200) planes, respectively, and they are all anatase signature peaks. The grain size for the TCM-1was $38.69 \mathrm{~nm}$ and it was determined from the full width at half maximum (FWHM) of the (101) anatase peak according to the Scherrer's formula. In our previous work, it was proven that the doping and the role of $\mathrm{Mn}$ in $\mathrm{TiO}_{2}$. in the case of $0.1 \mathrm{wt} \%$ manganese shows only 2+ oxidation state in comparison with high concentrations [34]. 


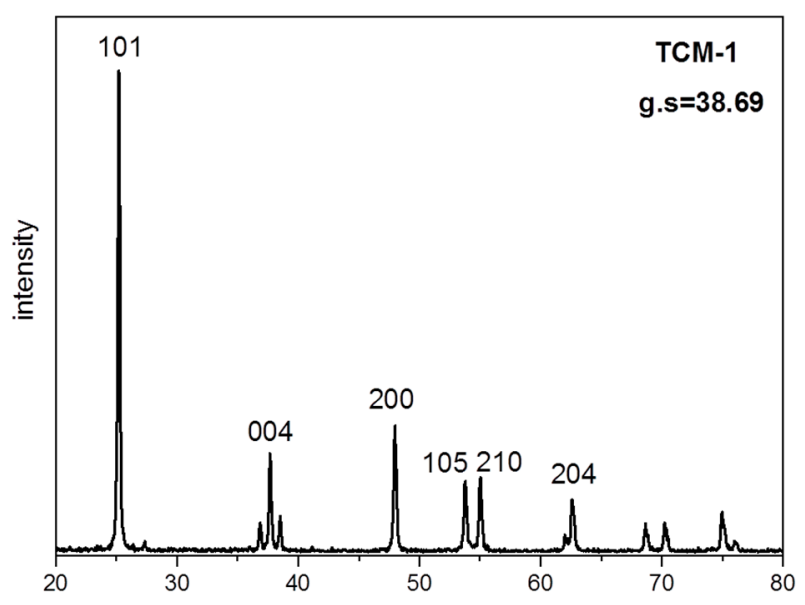

Figure 2. Powder XRD patterns of TCM-1.

Figure 3 shows the UV-Vis absorption as a function of wavelength for TCM- 1 and exhibited an absorption edge in the visible light range $(400-800 \mathrm{~nm})$. The band gap energy was $2.87 \mathrm{eV}$ for $\mathrm{Mn}$ doped catalyst.

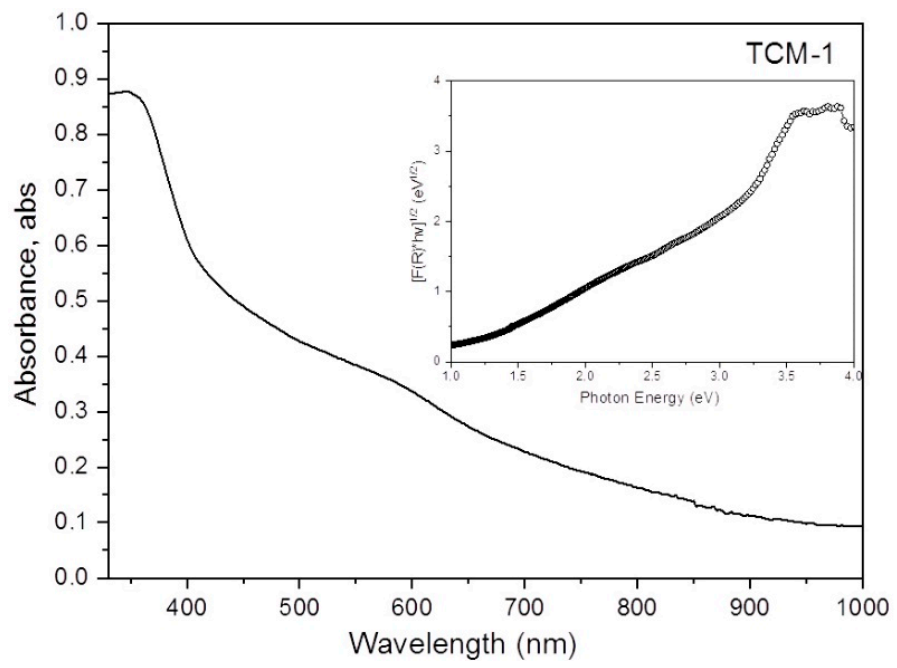

Figure 3. UV-vis absorption of TCM-1and energy gaps calculated from Kubenka-Munk plots.

Figure 4a shows the morphology of the photocatalyst were investigated with SEM, without specific morphology, while the spherical shape particles of all the samples demonstrated some degree of agglomeration and the diameter ranged from 0.1 to $40 \mu \mathrm{m}$. Figure $4 \mathrm{~b}$ shows the characteristic peaks of $\mathrm{Mn}$ and Ti atoms. 

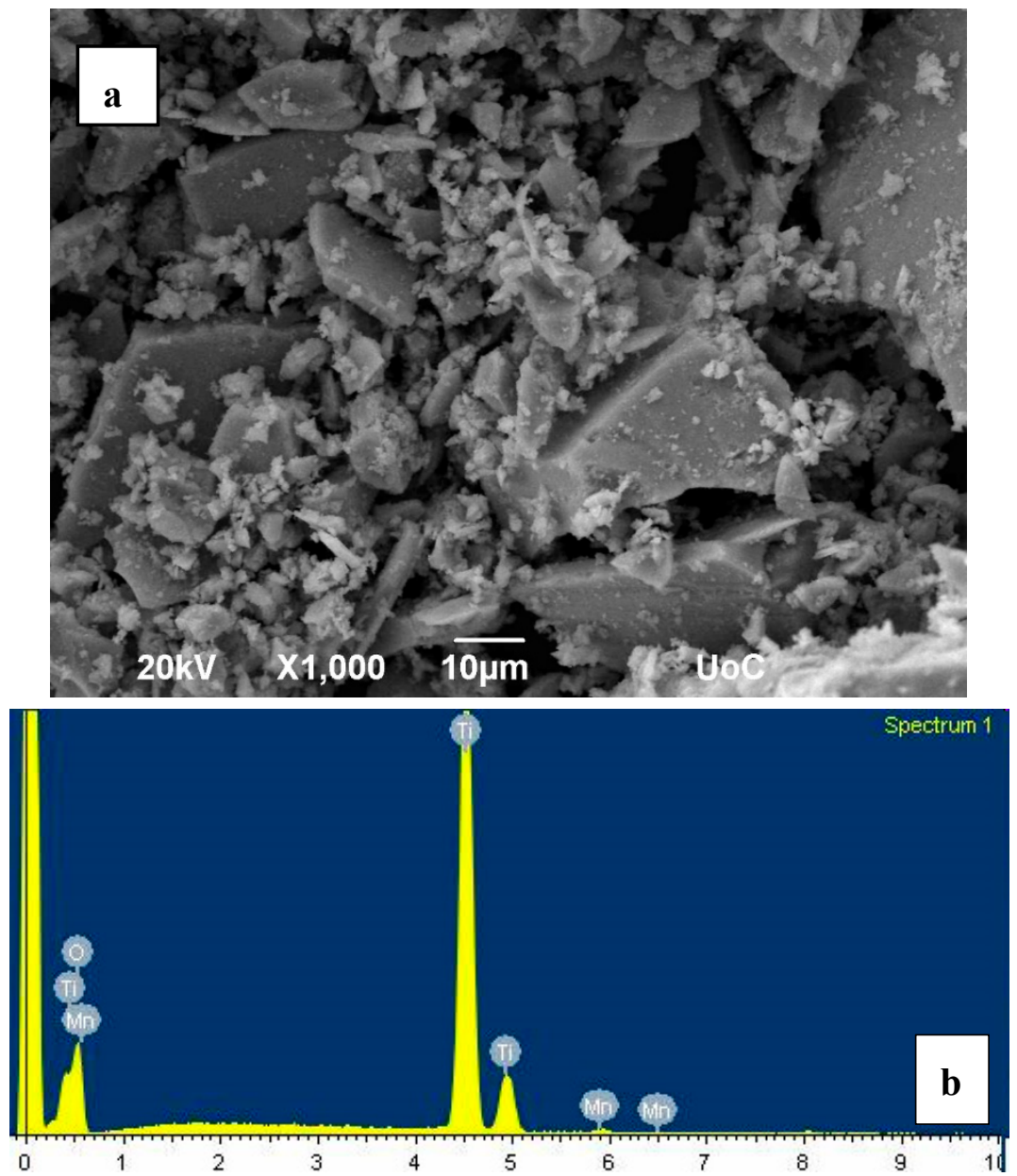

Figure 4. (a,b) SEM image of TCM-1 and EDX analysis.

As far as the photo-paint is concerned, the main physicochemical properties are listed in Table 1. The measured values are typical for an indoor emulsion architectural paint, and although TCM-1 was used at 10\% w/w, TCM-1 behaved as expected from a Titanium Oxide white pigment. A paint formulated with the process described in Section 2.2.2 and with the use of Ti Pure 902+ Titanium Oxide white pigment instead of TCM-1 has identical physicochemical properties.

Table 1. Physicochemical Properties of photo-paint.

\begin{tabular}{ccc}
\hline Property & Value & Test Method \\
\hline Viscosity at $25^{\circ} \mathrm{C}(\mathrm{KU})$ & $100-110$ & ASTM D 562 \\
Density at $25^{\circ} \mathrm{C}(\mathrm{kg} / \mathrm{l})$ & 1.55 & ISO 2811 \\
Fineness and Dispersion & $<40 \mu \mathrm{m}$ & ASTM D1210 \\
$\mathrm{pH}$ at $25^{\circ} \mathrm{C}$ & $8.5-9$ & ISO 787-9 \\
$\mathrm{PVC}(\%)$ & 66 & Calculated \\
Usage rate for a $50 \mu \mathrm{m}$ dry film thickness $\left(\mathrm{m}^{2} / \mathrm{kg}\right)$ & 5.95 & Calculated \\
\hline
\end{tabular}

\subsection{Lab and Real-Scale Photocatalytic Performance}

In order to estimate the background, experiments in the absence of the photocatlatyic paint were performed. The photocatalytic experiments determine the total pollutant degradation involving both UV photolysis and photocatalysis on the photo-paint. The net photocatalytic effect is calculated by the subtraction of the background contribution from the photocatalytic experiments. More specifically, blank tests were carried out by polluting the reactor with $\mathrm{NO}$ and Toluene in the absence of the 
photocatalyst without and with irradiation, respectively; then, the same experiments were carried out in the presence of the photocatalysts.

Figure $5 \mathrm{a}, \mathrm{b}$ present the elimination of $\mathrm{NO}$ and toluene under the irradiation of the photo-paint from Vis-light. It is obvious that just after the irradiation of the sample (Time 30), a sharp decrease in $\mathrm{NO}$ and a smaller but significant decrease in toluene concentration is observed, which demonstrate the immediate response of the photocatalytic system and provide the photo-efficiency of the paint.

Adsorption of NO onto the chamber's wall area and photolysis are the main sinks of NO during blank tests. Calculations have shown that both these mechanisms did not contributed to the total NO and toluene removal during the photocatalytic experiments.

The photocatalytic activity was evaluated by the calculation photocatalytic yield ( $\% \mathrm{n}$, Equation (2)) and photodegradation rate (r, Equation (3)). The corresponding equations were used for toluene. The results in Table 2 showed the possibility of developing a very promising and highly active to air pollutants photocalatylic paint (Table 2).

$$
\% \eta_{N O}^{\text {total }}=\frac{C_{N O}^{I N}-C_{N O}^{\text {OUT,light }}}{C_{N O}^{I N}} \times 100
$$

where:

$C_{N O}^{I N}$ : the concentration of $\mathrm{NO}$ at reactor inlet

$C_{N O}^{\text {OuT, light }}$ : the concentration of $\mathrm{NO}$ at reactor outlet under stable conditions with irradiation (lamp on)

The rate of photocatalytic yield of the material is calculated by the formula below (Equation (3)) and expressed in $\mu \mathrm{gm}^{-2} \mathrm{~s}^{-1}$ :

$$
r_{N O}^{\text {photo }}=\frac{613 F}{S}\left(\frac{\eta_{N O}^{\text {total }}}{\left(1-\eta_{N O}^{\text {total }}\right)}-\frac{\eta_{N O}^{\text {dark }}}{\left(1-\eta_{N O}^{\text {dark }}\right)}\right)
$$

where

$F$ : the gas flow $\left(\mathrm{m}^{3} \mathrm{~h}^{-1}\right)$

$S$ : The area of the test surface $\left(\mathrm{m}^{2}\right)$

The photodegradation rate provides a more accurate measure of the photocatalytic activity of the material in comparison with the \% photocatalytic decomposition. The latter is attributed to the fact that $r$ is taking into consideration the initial concentration of the pollutant, the sample's area and the irradiation time. It is expressed as $\mu \mathrm{g}$ of converted $\mathrm{NO} /$ toluene per $\mathrm{m}^{2}$ of material per second of irradiation. The current parameter was calculated only for the lab tests, where the pollutant flow rate in the chamber was known.

The losses in the system are minimal, and as a consequence the fraction $\frac{\eta_{N D}^{\text {dark }}}{\left(1-\eta_{N O}^{\text {dark }}\right)}$ is zero.

Table 2. Photocatalytic parameters for lab and real scale tests.

\begin{tabular}{ccccc}
\hline Parameter & \multicolumn{2}{c}{ Lab Scale } & \multicolumn{2}{c}{ Real Scale } \\
\hline & NO & Toluene & NO & Toluene \\
$\% \eta$ & 59.08 & 16.7 & 18.8 & 5.26 \\
rphoto $\left(\mu \mathrm{g} / \mathrm{m}^{2} \mathrm{~s}\right)$ & 3.89 & 1.05 & - & - \\
\hline
\end{tabular}




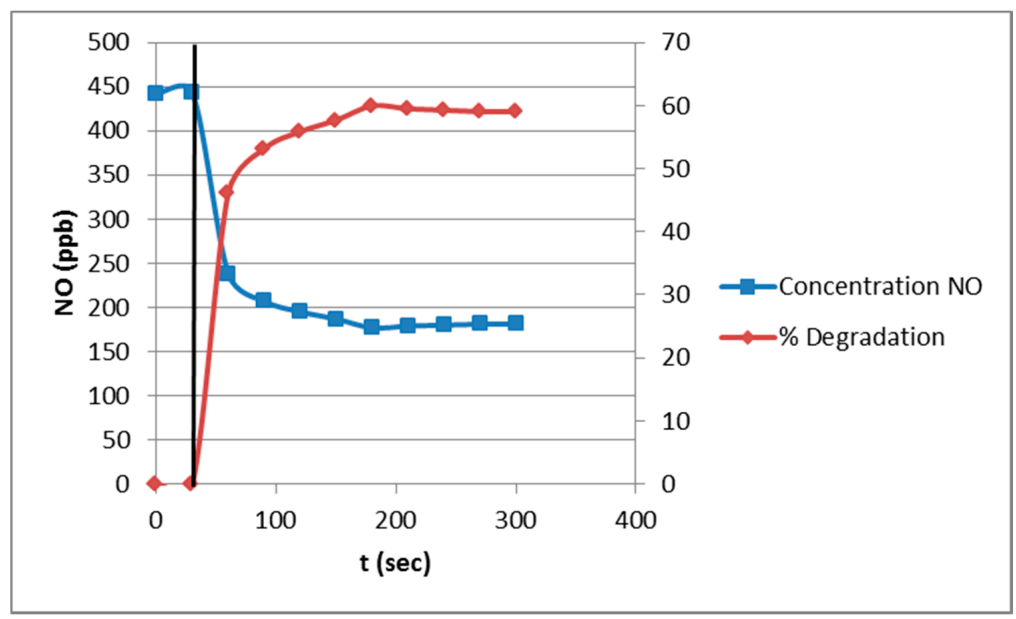

(a)

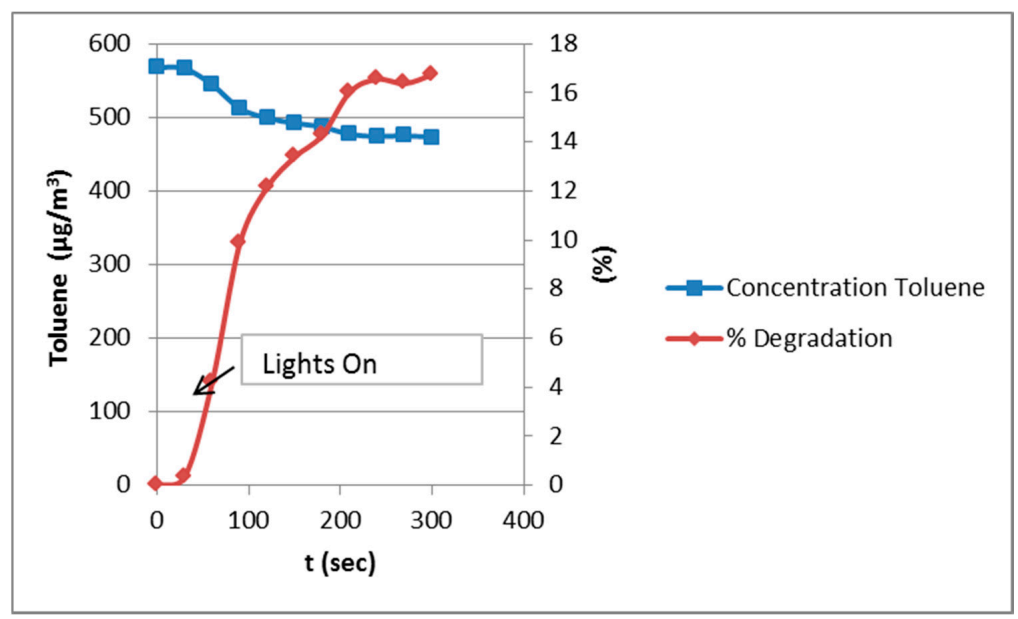

(b)

Figure 5. (a) Photocatalytic yields $(\% \eta)$ concentration profile versus time for the photo-oxidation of NO in the presence of the catalyst. (b) Photocatalytic yields $(\% \eta)$ concentration profile versus time for the photo-oxidation of Toluene in the presence of the catalyst.

The variations on $\mathrm{NO}$ and Toluene concentrations during the experimental procedure of photocatalysis are presented in Figure $5 a$ and Figure 5b, respectively. At first, the pollutant was introduced into the photo-reactor and the system remained in equilibrium for $30 \mathrm{~min}$. Then, irradiation was followed and a sharp reduction in NO and significant but less intense than NO elimination in toluene concentration is observed, which stabilized after $3 \mathrm{~h}$ and remained stable for approximately $2 \mathrm{~h}$ where the irradiation stopped. The results from the laboratory tests showed that for both pollutants, the photocatalytic paint gave very promising results. It is worth to note that in the case of toluene, the degradation efficiency is significantly lower than NO. However, a reduction of VOCs even at that level could have significant effects in the improvement of IAQ. Furthermore, the lower degradation efficiency in VOCs compare with NO is in line with the results of various studies [35-38]. The latter could be attributed to the low adsorption capacity of toluene molecules at the catalyst surface. The extremely hydroxylated surface of the paint material due to physically or chemically bound water, could constrain its interaction with the active radicals through surface diffusion [39,40].

\subsection{Real-Scale Photocatalytic Performance}

As far as the real scale application is concerned, the deppolution efficiency was calculated by the absolute difference in the concentration levels of $\mathrm{NO}$ and toluene, which was measured in the two 
rooms of the military building: the "green" and the "reference" rooms. Results are shown in Table 2. It is observed that real scale tests showed significant lower values of $\mathrm{NO}$ and toluene degradation than in the lab-scale application. The latter was also observed in other studies [41-45]. The control environment of the laboratory versus the more complex and polyparametric environment of a real application could be the main reason that led to significant differences in the values that characterize the photocatalytic efficiency of the paint. However, they provide an indication of the photocatalytic efficiency of the paints to degrade pollutants in situ and a basis for photo-paint applications in order to improve IAQ.

\section{Discussion}

The effect of photocatalytic paint in the improvement of IAQ has been studied in both laboratory and real scale tests. It is interesting to note that NO could be effectively converted by the photocatalytic paint, while toluene showed lower photocatalytic removal in the same photocatalytic process (lab and real scale). A possible explanation of the different photocatalytic performance of $\mathrm{NO}$ and toluene under the same application could be explained as follows: the dominant oxidants in a photocatalytic reaction are hydroxyl radicals $\left(\mathrm{OH}_{\bullet}\right)$ and hydroperoxyl radicals $\left(\mathrm{HO}_{2} \bullet\right)$, which are generated from the redox reactions of positive holes $\left(\mathrm{h}^{+}\right)$and electrons $\left(\mathrm{e}^{-}\right)$with $\mathrm{O}_{2}, \mathrm{H}_{2} \mathrm{O}$ or $\mathrm{OH}^{-}$. The kinetic coefficients of gas phase reactions for $\mathrm{HO}_{\mathrm{x}}$ radicals and targeted gas ( $\mathrm{NO}$ and toluene in this case) have only minor differences [46,47]. However, NO is better adsorbed by the alkaline constituents of the paint due to its acidic property. This significantly increases their reaction potential with $\mathrm{HO}_{\mathrm{x}}$ radicals. On the other hand, the adsorption capacity of toluene is lower than NO due to the extremely hydroxylated surface of the paint, which constrain its interaction with the active radicals. Toluene is absorbed more easily in a less hydrophilic $\mathrm{TiO}_{2}$ surface than a more hydroxylated one [41]. It is obvious that different gaseous pollutants present significant variations in their photocatalytic activity due to the difference in their diffusion in the paint matrix. Efficient adsorption of the pollutant molecules at the catalyst surface could promote the photocatalytic reaction.

Comparing lab versus real scale experiments results, it is observed that laboratory tests showed significant higher values of both pollutants ( $\mathrm{NO}$ and toluene) degradation than in real scale application. The translation from the laboratory results to "real" site efficiency is difficult because of the great number of parameters involved such as traffic and environmental parameters (temperature, light intensity, relative humidity wind speed). For that purpose, the more complex and polyparametric environment of a real application lead to significant differences in the values, which characterize the photocatalytic efficiency of the paint. In any case, precaution has to be taken with the interpretation of data obtained from the real scale experiments since these results are limited over time. However, they provide an indicative picture of the efficiency of the photocatalytic paints to eliminate air pollutants under real world conditions and a basis on which to improve their photocatalytic capacity for future applications. The need for large scale applications is more imperative nowadays, as many photo-materials have indicated very promising results during lab scale tests, but their capacity under real world conditions has not been proven. The latter is critical and proven by the outcome of the current work, which showed significant differences between the photo-efficiency of the same material under two different scales. Additionally, the demonstration of the effectiveness of photocatalytic materials on site should also include negative effects, such as the formation and emission of by-products during the photocatalytic reactions, as well as the durability of the photo-paint mechanical properties. The latter is of high importance, as in most of the cases, $\mathrm{TiO}_{2}$ oxidizes not only the air pollutants on the photo-material surface, but also their organic and inorganic components. For that purpose, special attention is given in the formulation of such materials in order to avoid it. As it is not in the scope of the current manuscript to study the durability of the photo-paint mechanical properties, measurements to characterize the mechanical durability of the paint were not performed. However, it is worth mentioning that almost two years after the photo-paint application, cracks or other surface damages have not been observed. Nevertheless, beyond the visual observation, the latter should be certified by analytical measurements, 
which should be the topic of future study. Furthermore, better results could be obtained by using mathematical models to simulate the photocatalytic processes, validating the model using the outcomes of the lab measurements and then implement various parameters in order to assess the real life effects [48].

\section{Conclusions}

This article addresses the effect of a photocatalytic paint on the elimination of air pollutants, and more specifically NO and toluene, for application in indoor environments. The following conclusions can be drawn:

- The physicochemical properties (including the mechanical parameters) of the photo-paint does not seem to be affected from the introduction of the photocatalytic powder (TCM-1) in the synthesis route.

- The photocatalytic efficiency of the paint on NO removal was significantly higher than toluene. The potential of a pollutant removal depends on the intrinsic properties of gas and the chemical nature of the paint in which the $\mathrm{TiO}_{2}$ particles are embedded. However, the removal rate of toluene was very promising for the improvement of IAQ while using the studied photo-paint.

- Lab tests showed better photocatalytic properties of the paint than the results from the real scale application due to the great number of parameters involved in the case of real scale application.

- There is a need for large scale applications to demonstrate the effectiveness of photocatalytic materials on site, including any negative effects of the application, such as the emission of by-products (e.g., carbonyl compounds, $\mathrm{O}_{3}$ etc.).

Author Contributions: Conceptualization, T.M., V.B. and G.K.; Data curation, T.M. and P.P.; Investigation, G.K.; Methodology, T.M., V.B., V.S. and A.T.; Project administration, V.B.; Writing—original draft, T.M.; Writing-review \& editing, T.M., V.B., V.S., A.T., P.P. and G.K.

Funding: This research was funded by the project "Intelligent technologies for enhancing Quality of Life through the provision of health monitoring at home and support for everyday life activities" (MIS 5002464), funded by the Operational Programme "Competitiveness, Entrepreneurship and Innovation" (NSRF 2014-2020) and co-financed by Greece and the European Union (European Regional Development Fund).

Conflicts of Interest: The authors declare no conflict of interest.

\section{References}

1. Ren, H.; Koshy, P.; Chen, W.-F.; Qi, S. Charles Christopher Sorrell Photocatalytic materials and technologies for air purification. J. Hazard. Mater. 2017, 325, 340-366. [CrossRef] [PubMed]

2. Zhang, Y.; Moa, J.; Li, Y.; Sundell, J.; Wargocki, P.; Zhang, J.; Little John, C.; Corsi, R.; Deng, Q.; Leung, M.H. Can commonly-used fan-driven air cleaning technologies improve indoor air quality? A literature review. Atmos. Environ. 2011, 45, 4329-4343. [CrossRef]

3. Bolashikov, Z.D.; Melikov, A.K. Methods for air cleaning and protection of building occupants from airborne pathogens. Build. Environ. 2009, 44, 1378-1385. [CrossRef]

4. Mamaghani, A.H.; Haghighat, F.; Lee, C.-S. Photocatalytic oxidation technology for indoor environment air purification: The state-of-the-art. Appl. Catal. B Environ. 2017, 203, 247-269. [CrossRef]

5. Fan, Z.; Lioy, P.; Weschler, C.; Fiedler, N.; Kipen, H.; Zhang, J. Ozone-initiatedreactions with mixtures of volatile organic compounds under simulatedindoor conditions. Environ. Sci. Technol. 2003, 37, 1811-1821. [CrossRef] [PubMed]

6. Boeniger, M.F. Use of ozone generating devices to improve indoor airquality. Am. Ind. Hyg. Assoc. J. 1995, 56, 590-598. [CrossRef] [PubMed]

7. Zhong, L.; Haghighat, F. Ozonation air purification technology in HVACapplications. ASHRAE Trans. 2014, 120 (Pt 1), 8 .

8. Bahri, M.; Haghighat, F.; Rohani, S.; Kazemian, H. Impact of design parameterson the performance of non-thermal plasma air purification system. Chem. Eng. J. 2016, 302, 204-212. [CrossRef] 
9. Bahri, M.; Haghighat, F. Plasma-based indoor air cleaning technologies: Thestate of the art-review. CLEAN-Soil Air Water 2014, 42, 1667-1680. [CrossRef]

10. Zhong, L.; Haghighat, F.; Lee, C.-S. Ultraviolet photocatalytic oxidation for indoor environment applications: Experimental validation of the model. Build. Environ. 2013, 62, 155-166. [CrossRef]

11. Farhanian, D.; Haghighat, F. Photocatalytic oxidation air cleaner: Identification and quantification of by-products. Build. Environ. 2014, 72, 34-43. [CrossRef]

12. Mo, J.; Zhang, Y.; Xu, Q. Effect of water vapor on the by-products anddecomposition rate of ppb-level toluene by photocatalytic oxidation. Appl. Catal. B Environ. 2013, 132-133, 212-218. [CrossRef]

13. Debono, O.; Thévenet, F.; Gravejat, P.; Héquet, V.; Raillard, C.; Le, L.; Locoge, N. Gas phase photocatalytic oxidation of decane at ppb levels: Removal kinetics, reaction intermediates and carbon mass balance. J. Photochem. Photobiol. A Chem. 2013, 258, 17-29. [CrossRef]

14. Ao, C.H.; Lee, S.C.; Mak, C.L.; Chan, L.Y. Photodegradation of volatile organic compounds (VOCs) and NO for indoor air purification using TiO2: Promotion versus inhibition effect of NO. Appl. Catal. B Environ. 2003, 42, 119-129. [CrossRef]

15. Ao, C.H.; Lee, S.C.; Zou, S.C.; Mak, C.L. Inhibition effect of $\mathrm{SO}_{2}$ on NOx and VOCs during the photodegradation of synchronous indoor air pollutants at parts perbillion (ppb) level by TiO2. Appl. Catal. B Environ. 2004, 49, 187-193. [CrossRef]

16. Selishchev, D.S.; Kolinko, P.A.; Kozlov, D.V. Adsorbent as an essential participant in photocatalytic processes of water and air purification: Computer simulation study. Appl. Catal. A Gen. 2010, 377, 140-149. [CrossRef]

17. Verbruggen, S.W. $\mathrm{TiO}_{2}$ photocatalysis for the degradation of pollutants ingas phase: From morphological design to plasmonic enhancement. J. Photochem. Photobiol. C Photochem. 2015, 24, 64-82. [CrossRef]

18. Ismail, A.A.; Bahnemann, D.W. Mesoporous titania photocatalysts: Preparation, characterization and reaction mechanisms. J. Mater. Chem. 2011, 21, 11686-11707. [CrossRef]

19. Hodgson, A.T.; Destaillats, H.; Sullivan, D.P.; Fisk, W.J. Performance of ultraviolet photocatalytic oxidation for indoor air cleaning applications. Indoor Air 2007, 17, 305-316. [CrossRef] [PubMed]

20. Muggli, D.S.; McCue, J.T.; Falconer, J.L. Mechanism of the photocatalytic oxidation of ethanol on TiO2. J. Catal. 1998, 173, 470-483. [CrossRef]

21. Mo, J.H.; Zhang, Y.P.; Xu, Q.J.; Zhu, Y.F.; Lamson, J.J.; Zhao, R.Y. Determination and risk assessment of by-products resulting from photocatalytic oxidation of toluene. Appl. Catal. B Environ. 2009, 89, 570-576. [CrossRef]

22. Kovalevskiy, N.S.; Lyulyukina, M.N.; Selishcheva, D.S.; Kozlova, D.V. Analysis of air photocatalytic purification using a total hazard index: Effect of the composite TiO2/zeolite photocatalyst. J. Hazard. Mater. 2018, 358, 302-309. [CrossRef] [PubMed]

23. Denny, F.; Permma, E.; Scott, J.; Wang, J.; Pui, D.Y.H.; Amal, R. Integrated Photocatalytic Filtration Array for Indoor Air Quality Control. Environ. Sci. Technol. 2010, 44, 5558-5563. [CrossRef] [PubMed]

24. Yu, H.; Zhang, K.; Rossi, C. Experimental Study of the Photocatalytic Degradation of Formaldehyde in Indoor Air using a Nano-particulate Titanium Dioxide Photocatalyst Indoor. Built Environ. 2007, 16, 529-537. [CrossRef]

25. Binas, V.D.; Sambani, K.; Maggos, T.; Katsanaki, A.; Kiriakidis, G. Synthesis and photocatalytic activity of Mn-doped $\mathrm{TiO}_{2}$ nanostructured powders under UV and visible light. Appl. Catal. B Environ. 2012, 113-114, 79-86. [CrossRef]

26. Cacho, C.; Geiss, O.; Barrero-Moreno, J.; Binas, V.D.; Kiriakidis, G.; Botalico, L.; Kotzias, D. Studies on photo-induced $\mathrm{NO}$ removal by $\mathrm{Mn}$-doped $\mathrm{TiO}_{2}$ under indoor-like illumination conditions. J. Photochem. Photobiol. A Chem. 2011, 222, 304-306. [CrossRef]

27. Karafas, E.S.; Romanias, M.N.; Stefanopoulos, V.; Binas, V.; Zachopoulos, A.; Kiriakidis GPapagiannakopoulos, P. Effect of metal doped and co-doped $\mathrm{TiO}_{2}$ photocatalysts oriented to degrade indoor/outdoor pollutants for air quality improvement. A kinetic and product study using acetaldehyde as probe molecule. J. Photochem. Photobiol. A-Chem. 2019, 371, 255-263. [CrossRef]

28. Binas, V.; Stefanopoulos, V.; Kiriakidis, G.; Papagiannakopoulos, P. Photocatalytic oxidation of gaseous benzene, toluene and xylene under UV and visible irradiation over Mn-doped TiO2 nanoparticles. J. Mater. 2019, 5, 56-65. [CrossRef]

29. Venieri, D.; Tournas, F.; Gounaki, I.; Binas, V.; Zachopoulos, A.; Kiriakidis, G.; Mantzavinos, D. Inactivation of Staphylococcus aureus in water by means of solar photocatalysis using metal doped $\mathrm{TiO}_{2}$ semiconductors. J. Chem. Technol. Biotechnol. 2017, 92, 43-51. [CrossRef] 
30. Venieri, D.; Gounaki, I.; Bikouvaraki, M.; Binas, V.; Zachopoulos, A.; Kiriakidis, G.; Mantzavinos, D. Solar photocatalysis as disinfection technique: Inactivation of Klebsiella pneumoniae in sewage and investigation of changes in antibiotic resistance profile. J. Environ. Manag. 2017, 195, 140-147. [CrossRef] [PubMed]

31. Venieri, D.; Gounaki, I.; Binas, V.; Zachopoulos, A.; Kiriakidis, G.; Mantzavinos, D. Inactivation of MS2 coliphage in sewage by solar photocatalysis using metal-doped $\mathrm{TiO}_{2}$. Appl. Catal. B Environ. 2015, 178, 54-64. [CrossRef]

32. Venieri, D.; Fraggedaki, A.; Kostadima, M.; Chatzisymeon, E.; Binas, V.; Zachopoulos, A.; Kiriakidis, G.; Mantzavinos, D. Solar light and metal-doped $\mathrm{TiO}_{2}$ to eliminate water-transmitted bacterial pathogens: Photocatalyst characterization and disinfection performance. Appl. Catal. B Environ. 2014, 154-155, 93-101. [CrossRef]

33. Binas, V.; Papadaki, D.; Maggos, T.; Katsanaki, A.; Kiriakidis, G. Study of innovative photocatalytic cement based coatings: The effect of supporting materials. Constr. Build. Mater. 2018, 168, 923-930. [CrossRef]

34. Binas, V.; Venieri, D.; Kotzias, D.; Kiriakidis, G. Modified $\mathrm{TiO}_{2}$ based photocatalysts for improved air and health quality. J. Mater. 2017, 3, 3-16.

35. Ramirez, A.M.; Demeestere, K.; De Belie, N.; Mäntylä, T.; Levänen, E. Titanium dioxide coated cementitious materials for air purifying purposes: Preparation, characterization and toluene removal potential. Build. Environ. 2010, 45, 832-838. [CrossRef]

36. Tsoukleris, D.S.; Maggos, T.; Vassilakos, C.; Falaras, P. Photocatalytic degradation of volatile organics on $\mathrm{TiO}_{2}$ embedded glass spherules. Catal. Today 2007, 129, 96-101. [CrossRef]

37. Kannangara, Y.Y.; Wijesena, R.; Rajapakse, R.G.M.; Nalin de Silva, K.M. Heterogeneous photocatalytic degradation of toluene in static environment employing thin films of nitrogen-doped nano-titanium dioxide. Int. Nano Lett. 2018, 8, 31-39. [CrossRef]

38. Pei, C.C.; Leung, W.W.-F. Photocatalytic oxidation of nitrogen monoxide and o-xylene by $\mathrm{TiO}_{2} / \mathrm{ZnO} / \mathrm{Bi}_{2} \mathrm{O}_{3}$ nanofibers: Optimization, kinetic modeling and mechanisms. Appl. Catal. B Environ. 2015, 174-175, 515-525. [CrossRef]

39. Chen, J.; Kou, S.-c.; Poon, C.-s. Photocatalytic cement-based materials: Comparison of nitrogen oxides and toluene removal potentials and evaluation of self-cleaning performance. Build. Environ. 2011, 46, 1827-1833. [CrossRef]

40. Ardizzone, S.; Bianchi, C.L.; Cappelletti, G.; Naldoni, A.; Pirola, C. Photocatalytic degradation of toluene in the gas phase: Relationship between surface species and catalyst features. Environ. Sci. Technol. 2008, 42, 6671-6676. [CrossRef] [PubMed]

41. Boonen, E.; Beeldens, A. Photocatalytic roads: From lab tests to real scale applications. Eur. Transp. Res. Rev. 2013, 5, 79-89. [CrossRef]

42. Beeldens, A. Air purification by pavement blocks: Final results of the research at the BRRC. In Proceedings of the Transport Research Arena Europe-TRA, Ljubljana, Slovenia, 21-24 April 2008.

43. Gignoux, L.; Christory, J.P.; Petit, J.F. Concrete roadways and air quality-Assessment of trials in Vanves in the heart of the Paris region. In Proceedings of the 12th International Symposium on Concrete Roads, Sevilla, Spain, 13-15 October 2010.

44. Maggos, T.; Plassais, A.; Bartzis, J.G.; Vasilakos, C.; Moussiopoulos, N.; Bonafous, L. Photocatalytic degradation of $\mathrm{NOx}$ in a pilot street canyon configuration using $\mathrm{TiO}_{2}$-mortar panels'. Environ. Monit. Assess. 2007, 136, 35-44. [CrossRef] [PubMed]

45. Maggos, T.; Bartzis, J.G.; Liakou, M. Gobin Photocatalytic degradation of NOx gases using $\mathrm{TiO}_{2}$-containing paint: A real scale study. J. Hazard. Mater. 2007, 146, 668-673. [CrossRef] [PubMed]

46. Atkinson, R.; Baulch, D.L.; Cox, R.A.; Crowley, J.N.; Hampson, R.F.; Hynes, R.G.; Jenkin, M.E.; Rossi, M.J.; Troe, J. Evaluated kinetic and photochemical data for atmospheric chemistry: Volume I-gas phase reactions of $\mathrm{O}_{\mathrm{x}}, \mathrm{HO}_{\mathrm{x}}, \mathrm{NO}_{\mathrm{x}}$ and $\mathrm{SO}_{\mathrm{x}}$ species. Atmos. Chem. Phys. 2004, 4, 1461-1738. [CrossRef]

47. Finlayson-Pitts, B.J.; Pitts, J.N. Chemistry of the Upper and Lower Atmosphere; Academic Press: San Diego, CA, USA, 2000.

48. Hunger, M.; Hüsken, G.; Brouwers, H.J.H. Photocatalytic degradation of air pollutants-from modeling to large scale application. Cem. Concr. Res. 2010, 40, 313-320. [CrossRef]

(C) 2019 by the authors. Licensee MDPI, Basel, Switzerland. This article is an open access article distributed under the terms and conditions of the Creative Commons Attribution (CC BY) license (http://creativecommons.org/licenses/by/4.0/). 